\title{
Laboreal
}

Volume 11 №2 | 2015

Varia

\section{Desigualdad de género y enfermedades profesionales en Bélgica}

A desigualdade de género e as doenças profissionais na Bélgica

L'inégalité de genre et les maladies professionnelles en Belgique

Gender inequality and occupational diseases in Belgium

\section{Laurent Vogel}

\section{(2) OpenEdition}

Journals

Edición electrónica

URL: http://journals.openedition.org/laboreal/3497

DOI: 10.4000/laboreal.3497

ISSN: 1646-5237

\section{Editor}

Universidade do Porto

\section{Referencia electrónica}

Laurent Vogel, «Desigualdad de género y enfermedades profesionales en Bélgica », Laboreal [En línea], Volume $11 \mathrm{~N}^{0} 2$ | 2015, Publicado el 01 diciembre 2015, consultado el 07 octubre 2019. URL : http:// journals.openedition.org/laboreal/3497; DOI : 10.4000/laboreal.3497

Este documento fue generado automáticamente el 7 octubre 2019.

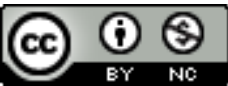

Laboreal está licenciado com uma Licença Creative Commons - Atribuição-NãoComercial 4.0 Internacional. 


\title{
Desigualdad de género y enfermedades profesionales en Bélgica
}

\author{
A desigualdade de género e as doenças profissionais na Bélgica \\ L'inégalité de genre et les maladies professionnelles en Belgique \\ Gender inequality and occupational diseases in Belgium
}

Laurent Vogel

\section{NOTA DEL EDITOR}

http://dx.doi.org/10.15667/laborealxi0215lv

Manuscrito recebido em: junho/2015

Aceite após peritagem: novembro/2015

\section{Introducción}

1 En un artículo anterior introduje elementos de análisis histórico sobre la evolución del reconocimiento de las enfermedades profesionales en Bélgica (Vogel, 2014). Un elemento central de este análisis indica que el proceso de reconocimiento se traduce en una distorsión de la percepción del impacto real de las condiciones de trabajo sobre la salud. Esta distorsión refleja, en gran medida, desigualdades sociales más profundas en el mundo del trabajo. Es así como el reconocimiento tan tardío de la silicosis por parte del derecho belga relativo a las enfermedades profesionales puede explicarse por el elevado porcentaje de trabajadores migrantes en las minas de carbón, por lo menos desde 1945. Los mecanismos jurídicos y una parte importante de los conocimientos médicos se vieron fuertemente influidos por este factor social. 
2 El análisis de género de la situación actual muestra que la construcción social de las enfermedades profesionales da como resultado una importante discriminación contra la mujer. Esta situación debilita la prevención de los problemas de salud en el trabajo en las ocupaciones y sectores donde se concentran mujeres. Además de reforzar el estereotipo según el cual el trabajo de las mujeres conlleva menos riesgos que el de los hombres (Messing, 2015).

\subsection{Desigualdades incuestionables}

\subsubsection{Precisiones metodológicas}

3 Los informes anuales del Fondo de Enfermedades Profesionales (FMP, por sus siglas en francés), hacen la distinción entre hombres y mujeres solamente a partir de 2002, lo que permite evaluar estadísticamente el alcance de las posibles desigualdades. Los datos anteriores a 2002 no pueden utilizarse para llevar a cabo un análisis cuantitativo de género.

4 Recurriendo a la terminología económica, los datos permiten medir la situación en términos de flujo y stock. La medición en términos de flujo: corresponde a todos los nuevos casos procesados durante un año, las decisiones y los gastos. La medición en términos de inventario o stock: consiste en los datos acumulados en relación con el conjunto de indemnizaciones durante un determinado año. Estos datos en términos de stock son más completos, ya que una persona indemnizada por una enfermedad profesional durante los años anteriores tiene probabilidades de continuar recibiendo dicha indemnización a lo largo de su vida y, después de su fallecimiento, sus beneficiarios pueden recibir las prestaciones.

5 La comparación de los datos en términos de flujo y de stock hace posible verificar si han surgido nuevas tendencias. Podría considerarse que las desigualdades entre hombres y mujeres son principalmente secuelas del pasado. En este caso, los datos en términos de stock conllevarían desigualdades significativas, mientras que los datos correspondientes al flujo serían mucho más igualitarios ${ }^{1}$.

6 Este análisis se centra en los casos de incapacidad laboral permanente, que son los más numerosos y representan el coste financiero más importante. En 2012, de un total superior a los 281 millones de euros en gastos de seguro de parte del FMP, los reconocimientos de una enfermedad profesional causante de una incapacidad permanente representaron poco más de 201 millones $(71,5 \%)^{2}$. Los relacionados con una incapacidad temporal representaron solamente un importe aproximado de 12,7 millones (alrededor del 4,5\%). Los gastos relacionados con los fallecimientos ascendieron a 61 millones (21,7\%). Casi todos los fallecimientos se produjeron como consecuencia de una enfermedad ya reconocida como causa de una incapacidad permanente. Otros gastos de seguros (asistencia sanitaria o medidas para retirar del trabajo a los trabajadores afectados por enfermedades profesionales) representan importes muy reducidos. Por lo tanto, las cifras aquí examinadas representan más del $90 \%$ de los gastos de seguro del FMP, lo que justifica el que no se aborden aquí los gastos relacionados con la incapacidad temporal ni las medidas de prevención.

7 Los datos no permiten identificar indicadores de frecuencia en relación con la población asegurada, la cual se compone de todas las personas que trabajan o han trabajado durante un periodo de su vida en el sector privado o en las administraciones 
locales o provinciales ${ }^{3}$. Así, puede compararse a los hombres y mujeres indemnizados, pero es imposible relacionar estas cifras con la proporción de hombres y mujeres de la población asegurada. Se podría considerar razonablemente que las diferencias de poca magnitud no implican necesariamente una desigualdad. En el caso de algunas enfermedades, existen diferencias objetivas que determinan variaciones enormes entre hombres y mujeres. La silicosis es más frecuente entre los hombres y las enfermedades infecciosas entre las mujeres debido a la composición de los grupos profesionales afectados. En cambio, las grandes diferencias que se constatan en el conjunto de la población activa para la suma de enfermedades reconocidas (en torno al $90 \%$ de hombres y el $10 \%$ de mujeres para las enfermedades indemnizadas) no pueden explicarse por diferencias objetivas en la composición de la población correspondiente.

\subsubsection{Datos en términos de flujo}

8 El proceso que lleva a una posible indemnización comienza ya sea por la declaración de un médico del trabajo, o porque la ha reclamado el paciente (o sus derechohabientes).

9 La declaración de los médicos del trabajo es obligatoria para todo tipo de patología para la que se sospecha al menos una causa provocada por el ejercicio de la profesión. Concierne asimismo al sector público. Esta obligación se respeta en muy pocas ocasiones si se considera que cerca de $70 \%$ de los trabajadores en Bélgica están cubiertos por la vigilancia sanitaria por parte de la medicina del trabajo ${ }^{4}$. Este es el único ámbito para el que el informe estadístico del FMP cubre tanto el sector privado en su conjunto como el sector público. Se observa una reducción constante del número de declaraciones entre 1994 y 2009, lo que resulta tanto más preocupante en la medida en que el número de trabajadores sujetos a la vigilancia sanitaria aumentó notablemente debido a la evolución de la normativa en vigor. En el curso de los últimos cuatro años se ha iniciado una recuperación. En 2013 se registraron 2.978 declaraciones, de las cuales aproximadamente la mitad correspondían a las mujeres. En este ámbito, no se observa una desigualdad significativa y, de un año a otro, el porcentaje de mujeres es bastante estable. Resulta inquietante comprobar que la mayoría de las declaraciones se refieren únicamente a las enfermedades enumeradas en la "lista". Las enfermedades que no figuran en la lista (que podrían ser reconocidas en el marco del sistema abierto ${ }^{5}$ ) representan poco menos del 7\% de los casos notificados en 2013. Una de las funciones de la declaración obligatoria es establecer un mecanismo eficaz de vigilancia sanitaria que permita supervisar la evolución de las patologías causadas por las malas condiciones de trabajo, con un interés colectivo doble: mejorar la prevención y acelerar la revisión de la lista. Parece que los médicos del trabajo no interpretan correctamente su papel y solamente consideran la posibilidad de formular la declaración en relación con la probabilidad de obtener una indemnización por enfermedad. Esta hipótesis se ve corroborada por la observación de que el aumento significativo en el número de declaraciones de los médicos del trabajo en 2013 se explica solamente por una patología. En 2013, el número de declaraciones de tendinitis se eleva bruscamente a 1.133 casos (más de un tercio de las declaraciones), mientras que en el sistema abierto, en cuyo marco las tendinitis debían haberse declarado obligatoriamente antes de la modificación de la lista en 2012, el número total de enfermedades declaradas se limitó a 392 en 2011, a 242 en 2012 y a 203 en $2013^{6}$. La única explicación no se debe, evidentemente, a un repentino deterioro de las condiciones de trabajo, sino a la renuencia de los médicos del trabajo a declarar 
enfermedades cuya indemnización se considera incierta. Las declaraciones de enfermedades profesionales para las mujeres se concentran de manera muy típica en el sector de la sanidad y servicios sociales. Otros sectores - con fuerte concentración de mujeres- permanecen en una zona de invisibilidad. Se pueden citar los ejemplos del comercio y de la limpieza.

Las solicitudes iniciales de indemnización por incapacidad laboral son introducidas por la persona asegurada, ya sea directamente, o a través de otra persona o institución. En caso de declaración por un médico del trabajo, el FMP tiene que contactar al trabajador e informarle sobre la posibilidad de introducir una solicitud de indemnización. A pesar del papel importante atribuido a la medicina del trabajo en los procesos de indemnización de enfermedades profesionales, las estadísticas del FMP muestran la baja participación de los médicos del trabajo, a los que corresponde el 10,3\% de las solicitudes de 2013. El papel de las mutuas es sorprendentemente bajo, ya que representa el $8,3 \%$ de las solicitudes ${ }^{7}$. Los médicos de cabecera cuentan en su haber el $15,2 \%$ de las solicitudes. Estos datos dan pie para asumir cierta soledad de parte de las víctimas, que cuentan con un apoyo insuficiente por parte de las instituciones ${ }^{8}$. En esta etapa, no puede distinguirse entre enfermedades que causan una incapacidad permanente de las enfermedades que causan una temporal. Una solicitud relativa a una enfermedad de la lista puede ser recalificada y ser objeto de una decisión positiva en el sistema abierto o viceversa.

11 En 2012, todas las solicitudes presentadas en el sistema privado en relación con una incapacidad laboral ascendieron a 6.295 , con $29 \%$ de mujeres. Se observaron diferencias significativas entre hombres y mujeres en relación con las patologías que son objeto de esta solicitud. Para los hombres, las tres categorías más importantes son los trastornos lumbares (873 casos), la sordera ( 776 casos) y problemas respiratorios (765 casos). En lo que respecta a las mujeres, solamente dos grupos superaron los 200 casos: la tendinitis (523 casos) y el síndrome del túnel carpiano (459). En las administraciones provinciales y locales, las mujeres son más numerosas que los hombres a introducir una primera solicitud (415 casos contra 267). Aun cuando el síndrome del túnel carpiano sigue siendo el motivo principal de las solicitudes de las mujeres ( 99 casos), es seguido de cerca por los trastornos respiratorios (91 casos) y la tendinitis ( 85 casos).

La comparación con 2013 es significativa. Las solicitudes presentadas se incrementaron considerablemente (10.134 casos) y el porcentaje de mujeres también aumentó de forma significativa (38\%). Este fenómeno se debe íntegramente a la inclusión de las tendinitis en la lista de enfermedades profesionales, las cuales motivaron 3.745 solicitudes (con aproximadamente el $53 \%$ de mujeres). Por sí solas, las tendinitis representaron poco más de la mitad de las solicitudes presentadas por las mujeres (1.972 de 3.869 solicitudes). En 2014 se observa la misma tendencia, con 9.545 solicitudes presentadas (de las cuales 3164 corresponden a tendinitis). Estas cifras demuestran la importancia de las revisiones periódicas de la lista en la lucha contra la discriminación de género.

13 La mayoría de las solicitudes presentadas son rechazadas por el FMP tanto en el sistema abierto como en el sistema de lista. En el sector privado, se rechazaron 4.847 solicitudes en el sistema de lista en 2013 (con cerca del 40\% de mujeres) en relación con 2.987 decisiones positivas. Los datos de 2014 son similares: 5.095 rechazos, cuyo $40 \%$ eran solicitudes femeninas. Entre hombres y mujeres se observa una diferencia significativa en cuanto a la tipología de las decisiones positivas. Para los hombres, más de la mitad 
de las decisiones positivas implican el reconocimiento de una incapacidad permanente (1.002 casos en relación con 1.981 en 2013). Para las mujeres, el número de incapacidades permanentes reconocidas representa aproximadamente el $10 \%$ de las decisiones positivas (100 casos sobre 1006). La proporción entre hombres y mujeres en términos de decisiones positivas que reconocen una incapacidad permanente fue de 10 a 1 en 2012. Con la posibilidad de reconocimiento de la tendinitis, se modificó ligeramente. En 2014, las primeras decisiones positivas que reconocen una incapacidad permanente en el sector privado ascendieron a 884, con 752 hombres y 132 mujeres (relación aproximada de 6 hombres por cada mujer). La evolución se debe a una sola entrada en la lista, la relativa a la tendinitis (con 99 mujeres y 159 hombres).

Tabla 1: primeras decisiones positivas de indemnización de una incapacidad permanente por una enfermedad profesional de la lista en el sector privado

\begin{tabular}{|c|c|c|c|c|c|c|}
\hline & $\begin{array}{l}2013 \\
\text { hombres }\end{array}$ & $\begin{array}{l}2013 \\
\text { mujeres }\end{array}$ & $\begin{array}{l}2013 \\
\text { total }\end{array}$ & $\begin{array}{l}2014 \\
\text { hombres }\end{array}$ & $\begin{array}{l}2014 \\
\text { mujeres }\end{array}$ & $\begin{array}{l}2014 \\
\text { total }\end{array}$ \\
\hline $\begin{array}{l}\text { EP causadas por una lista de } \\
\text { varios agentes quimicos }\end{array}$ & 13 & 2 & 15 & 6 & 2 & 8 \\
\hline $\begin{array}{l}\text { EP de la piel causadas por } \\
\text { otros agentes }\end{array}$ & 6 & 7 & 13 & 7 & 7 & 14 \\
\hline $\begin{array}{l}\text { EP por inhalacion causadas por } \\
\text { otros agentes }\end{array}$ & 345 & 12 & 357 & 272 & 13 & 285 \\
\hline EP por agentes biologicos & 0 & 1 & 1 & 0 & 0 & 0 \\
\hline $\begin{array}{l}\text { EP causadas por agentes físicos } \\
\text { (entre paréntesis tendinitis) }\end{array}$ & $\begin{array}{l}636 \\
(89)\end{array}$ & $\begin{array}{l}66 \\
(45)\end{array}$ & $\begin{array}{l}702 \\
(134)\end{array}$ & $\begin{array}{l}463 \\
(159)\end{array}$ & $\begin{array}{l}108 \\
(99)\end{array}$ & $\begin{array}{l}571 \\
(258)\end{array}$ \\
\hline Otras EP & 2 & 12 & 14 & 4 & 2 & 6 \\
\hline Total & 1002 & 100 & 1102 & 752 & 132 & 884 \\
\hline
\end{tabular}

El año 2006 registró el número más bajo en lo que se refiere a las decisiones positivas que reconocen una incapacidad permanente (844 casos) en relación con un nivel máximo en 1992 (4.888 casos). La reducción dramática de la cantidad de decisiones positivas se explica por dos factores: la paulatina reducción de casos de silicosis (con el cierre de las minas de carbón, los nuevos casos son excepcionales) y la revisión de los criterios de la lista sobre las enfermedades causadas por vibraciones mecánicas. Las decisiones positivas por incapacidad permanente en el caso de enfermedades causadas por agentes físicos son las que han experimentado los mayores cambios en los últimos veinte años. Representaban cerca de 4.000 casos en 1992 y se han mantenido en torno a 500 casos desde 2006, pero con un aumento correspondiente al reconocimiento de las tendinitis a partir de 2013. Las revisiones, intervenidas en 2002 y en 2004, de los códigos de los trastornos dorsolumbares han reducido significativamente el número de decisiones positivas. 
15 En el sistema abierto, el número de decisiones positivas es bajo. En 2012, se rechazaron 1.517 solicitudes relativas en su gran mayoría a dos grupos de patologías: patologías óseas, articulares y discales y tendinitis. Alrededor del $30 \%$ de las solicitudes rechazadas concernían a las mujeres. Las mujeres dependen más que los hombres del sistema abierto: en el sistema de lista se han reconocido 63 incapacidades permanentes, en relación con 113 en el sistema abierto. Dado que es posible ahora reconocer la tendinitis como parte de la lista, el sistema abierto solo desempeña un papel residual y marginal. En 2014, hizo posible el reconocimiento de 21 casos de incapacidad permanente (19 hombres y 2 mujeres) y 10 casos de incapacidad temporal ( 9 hombres y 1 mujer).

16 Si se examinan las solicitudes presentadas a raíz de un fallecimiento, la desigualdad entre hombres y mujeres es enorme: 1.397 solicitudes rechazadas en 2012 sobre la base del sistema de lista en el sector privado, en las que figuran solamente 42 mujeres (alrededor del 3\%). Las 459 decisiones positivas reflejan una proporción comparable: 7 conciernen a las mujeres, es decir, menos del $2 \%$. En el caso de los hombres, la silicosis sigue siendo la causa principal de estas solicitudes (850 casos), seguida del mesotelioma (154 casos). Para las mujeres, solamente el mesotelioma supera los 10 casos (16 casos en 2012). El reducido porcentaje de mujeres puede explicarse por el efecto combinado de dos factores: una causa histórica (pocas mujeres estuvieron expuestas a la silicosis en el siglo XX como consecuencia de la ley del 5 de junio de 1911 que prohibía a las mujeres actividades de trabajo bajo la tierra) y una causa actual (la invisibilidad social de la mayoría de los cánceres profesionales que afecta de manera más importante a las mujeres, pero también a los hombres).

17 En general, el control judicial interviene solamente en un reducido número de solicitudes rechazadas. En 2011 y 2012 las impugnaciones judiciales ascendieron a 1.267 (de las cuales 207 en el marco del sistema abierto). No se impugnaron más de cuatro de cada cinco decisiones de rechazo. Nunca se han estudiado las razones que explican esta situación. Tomando como base estudios publicados en otros países, cabe suponer que existe una gran variedad de factores: debilitamiento de la persona enferma, insuficiencia de los servicios jurídicos de los sindicatos, dificultades para aportar la prueba en el caso del sistema abierto y, a pesar del principio de presunción, para establecer el riesgo profesional de determinadas patologías que figuran en el sistema de lista.

\subsubsection{Datos en términos de stock}

18 En estos datos se percibe una mayor huella de las actividades industriales que predominaron en el pasado. Este es precisamente el caso de la silicosis. En $2012^{9}$, con 7.150 casos, las indemnizaciones por concepto de incapacidad permanente en relación con la silicosis representaron más del 13\% del total de casos y casi el 18\% del total de las cantidades abonadas. Las mujeres representaron menos del 0,4\% de estos casos.

19 El caso de los trastornos músculo esqueléticos es diferente. Estas patologías están lejos de pertenecer al pasado. Las condiciones actuales de reconocimiento no se adaptan a la mayoría de las situaciones. En el sector privado, se registraron en 2012 alrededor de 26.000 casos de incapacidad permanente debido a los daños causados por las vibraciones mecánicas. La gran mayoría de los casos indemnizados lo fueron antes de 2002. Después de esta fecha, los diversos códigos han sido reemplazados por otros 
nuevos, los cuales solamente abren la posibilidad de un número muy limitado de indemnizaciones. De acuerdo con los criterios indicativos del FMP, solamente los trabajadores con lesiones importantes manifestadas antes de la edad de 40 años pueden ser indemnizados por concepto de lesiones lumbares causadas por vibraciones mecánicas. Las posibilidades de reconocimiento de una enfermedad profesional causada por la manipulación manual de cargas o por el estrés postural son sumamente limitadas y dependen del sistema abierto. Estas limitaciones contribuyen a excluir en gran medida a las mujeres de la indemnización por patologías dorsales o lumbares.

En lo que se refiere al stock, las desigualdades entre hombres y mujeres pueden constatarse con toda claridad. Entre las 52.950 personas indemnizadas por incapacidad permanente en el sector privado mediante el sistema de lista, 4.510 eran mujeres, es decir, en torno al $8,5 \%$. Por otra parte, la tasa media de incapacidad permanente de las mujeres es inferior a la de los hombres, ésta corresponde al 15,3\% en relación con el $18,5 \%$.

21 Las diferencias en el sistema abierto son menos pronunciadas, pero siguen siendo importantes. En 2012, para un total de 1.306 personas en el sector privado, se indemnizaron 422 mujeres (32\%) por incapacidad permanente. En el sistema abierto, también se observa una diferencia en las tasas de discapacidad que es desfavorable a las mujeres ( $8 \%$ en relación con un 9,2\% para los hombres).

Una menor tasa de incapacidad conlleva consecuencias jurídicas. De hecho, las prestaciones no son totalmente proporcionales a esta tasa de incapacidad. Se reducen a la mitad si la tasa es inferior al 5\% y a una cuarta parte cuando se sitúa entre un 5 y un 9\%. De todos los casos conocidos, la probabilidad de que la indemnización de las mujeres se vea reducida es mayor que la de los hombres.

Si se suman los casos indemnizados por incapacidad permanente en el sistema abierto y el sistema de lista, se obtiene un porcentaje del $9 \%$ de las mujeres en el sector privado. Queda claramente de manifiesto que este porcentaje es considerablemente menor que el porcentaje de mujeres que trabajan o han trabajado en este sector.

En cuanto a las indemnizaciones por fallecimiento, los datos del FMP no especifican el sexo de la persona fallecida. Identifican el sexo del cónyuge. Cabe suponer que, en la gran mayoría de los casos, se trataba de parejas heterosexuales. De asumirse que el sexo de la persona fallecida es diferente al del cónyuge, se calcula que se han concedido indemnizaciones por fallecimiento a la pareja de 11.260 hombres, en relación con el cónyuge de 96 mujeres (menos del 1\%). Esta es una paradoja común en la seguridad social: el único "beneficio" que las mujeres obtienen de la desigualdad tiene relación con los derechos derivados. De hecho, es una forma de subvencionar la institución de la familia con todas las desigualdades cuya reproducción permite.

\subsection{Hipótesis sobre la producción jurídica de esta desigualdad}

Explicar estos datos mediante criterios objetivos parece poco probable. Las encuestas sobre las condiciones de trabajo no permiten indicar objetivamente que las mujeres estarían expuestas 10 veces menos que los hombres a los diferentes factores de riesgo susceptibles de causar una enfermedad profesional provocando una incapacidad permanente ${ }^{10}$. Del mismo modo, los datos de los países vecinos donde las condiciones de trabajo y la distribución de hombres y mujeres entre los diversos sectores y grupos son 
comparables a las de Bélgica, obligan a descartar una explicación objetiva en términos sanitarios.

Cabe cuestionar las normas y prácticas relativas a su aplicación. En el marco de este artículo me centraré en el análisis de los mecanismos jurídicos, sin dejar de tener presente que éstos interactúan constantemente con factores no jurídicos ${ }^{11}$.

\subsubsection{Las disposiciones legislativas}

\subsubsection{Sistema general legislativo}

La disposición legal de la Ley de 24 de diciembre de 1963 ha sido brevemente descrita por Danièle De Brucq como sigue:

a. "La presunción iuris et de iure da una solución al problema de la causalidad aportando la ventaja de imposibilitar una controversia sobre la existencia o no existencia de la relación de causalidad, una vez que se establece que la víctima se vio expuesta al riesgo de la enfermedad propiamente dicha durante un corto período;

b. y en contraparte, la reparación del daño que es (como en el accidente de trabajo) fija, es decir, parcial;

c. La generalización de la reparación a todas las industrias en las que la víctima se ha visto expuesta al riesgo de la enfermedad contraída;

d. y, en contrapartida la contribución única invariable, denominada de solidaridad, que distribuye el coste del riesgo, y solidariza a todos los empresarios haciendo que participen en los daños causados en las empresas más peligrosas. Este sistema permite una reducción de la carga sumamente pesada que de otro modo pesaría solamente sobre las empresas más peligrosas". (De Brucq, 1998).

Este análisis determina lo esencial, aun cuando la jurisprudencia y las modificaciones legislativas posteriores puedan contradecir su optimismo. Sin embargo, es preciso añadir un elemento importante que crea un desequilibrio desfavorable para los trabajadores, es decir, la inmunidad civil concedida a los empleadores. Esta crítica merecería que se comentara ampliamente, tanto desde una perspectiva histórica como en derecho comparado. Me limitaré aquí a lo esencial. La formulación tiene la intención de evitar una inmunidad incondicional y total. Incluso prevé la subrogación del Fondo a los derechos de la víctima equivalente a las cantidades que ya haya abonado ${ }^{12}$. En la práctica, las excepciones previstas por la ley formulan condiciones imposibles de cumplir. La culpa intencional en lo que se refiere a las enfermedades profesionales puede imaginarse en los tratados teóricos o en las novelas de detectives. Nunca aparece en la jurisprudencia. Ni siquiera las violaciones conscientes y caracterizadas de obligaciones específicas de prevención tienen la posibilidad de ser tipificadas como culpa intencional. Las adiciones posteriores se refieren a hipótesis de tal improbabilidad ${ }^{13}$ que apenas se distinguen de la condición imposible de cumplir. En cuanto a la supuesta simetría entre la culpa intencional del trabajador y la del empleador, es artificial. Equivale a negar que es el empleador el que determina la organización del trabajo, la elección de los procesos de producción y las sustancias utilizadas. Por otra parte, no se entiende por qué la inmunidad del empleador cubre también elementos del daño, como la ansiedad, que está excluida para la indemnización de las enfermedades profesionales ${ }^{14}$. 


\subsubsection{Una definición que tarda en llegar} consiste una enfermedad profesional. Señala: "el Rey elabora la lista de las enfermedades profesionales, que se traducen en la reparación del daño" (artículo 30 de las leyes coordinadas de 3 de junio de 1970). Menciona otra posible fuente: las enfermedades profesionales sujetas a un convenio internacional obligatorio debidamente ratificado por Bélgica. Originalmente, durante los debates que precedieron a la Ley de 1927, esta ausencia de definición legal se presentó como una disposición provisional (Ugeux, 1995). La situación era urgente. Era preciso crear las condiciones para la ratificación del Convenio núm. 18 de la OIT y los conocimientos médicos no eran suficientemente precisos como para crear una definición jurídica adecuada. El Ministro de Trabajo había tenido que calmar al Parlamento: “¿Por qué, pues, pedirnos contar con definiciones indiscutibles antes de actuar?". Ochenta y cinco años más tarde, continuar con esta situación no deja de tener inconvenientes. Los reales decretos que definen las enfermedades enumeradas en la lista no son susceptibles de ser controlados por el Consejo de Estado, salvo en caso de vicios de forma o, eventualmente, una ilegalidad en virtud de otras disposiciones legislativas. En Francia, por el contrario, la jurisprudencia del Consejo de Estado ha permitido una mejor supervisión de la producción normativa. Los decretos pueden ser anulados cuando formulan condiciones contrarias a la ley ${ }^{15}$.

La introducción del sistema abierto implicaba necesariamente que se formulara un criterio, el cual fue establecido por el artículo 30 bis: es una enfermedad que encuentra su causa determinante y directa en el ejercicio de la profesión. La obligación de demostrar la relación de causalidad entre la enfermedad y el riesgo profesional recae, en este caso, en la víctima.

\subsubsection{El criterio de riesgo profesional}

El artículo 32 de las leyes coordinadas constituye el punto más débil de la construcción legislativa. Su aplicación conduce a un planteamiento en dos etapas. Sobre la base de los artículos 30 y 30 bis ha de examinarse si existe una enfermedad profesional. En la práctica, significa que es preciso referirse a la lista o a las pruebas aportadas en el sistema abierto. En segundo lugar, se considerará que cabe indemnizar esta enfermedad únicamente si se establecen los criterios jurídicos que definen el "riesgo profesional". La formulación de este artículo ha sido revisada varias veces ${ }^{16} \sin$ llegar nunca a una solución satisfactoria desde el punto de vista de la coherencia general de la ley. Esta se basa en un principio de presunción irrefutable de la causalidad cuando una situación está cubierta por la lista. De hecho, se observa que pueden presentarse tres situaciones principales:

a. la lista define una exposición sin relacionar con ella una patología en particular (por ejemplo, las enfermedades causadas por el benceno);

b. la lista define una patología que deja abierta la determinación de las exposiciones que la provocan (por ejemplo, las enfermedades cutáneas causadas por sustancias no consideradas en otros epígrafes) ;

c. la lista define tanto una exposición como una patología (ya sea de forma explícita: cánceres de pulmón o laringe causados por el amianto, o implícitamente, la silicosis) 

estadísticas no hacen posible distinguir entre los procedimientos relativos a la lista y los que se basan en el sistema abierto en función de las patologías. Por lo tanto, existe un alto grado de incertidumbre. De 1.203 resoluciones judiciales dictadas en $2011 \mathrm{y}$ 2012, 346 se referían a las patologías lumbares (definidas, sin embargo, muy detalladamente en la lista), 169 a los trastornos óseos y articulares, 133 a las patologías respiratorias (por lo general asociadas en la lista a agentes causales), 108 al síndrome del túnel carpiano. Desde un punto de vista más cualitativo, nuestra propia experiencia con los representantes sindicales y los médicos del trabajo, nos indica que el FMP suele rechazar regularmente enfermedades para las que se ha formulado una exposición explícita (en particular, un número significativo de cánceres de pulmón causados por el amianto).

Es como si la presunción establecida por la ley tendiera a desaparecer cuando se planteara una etiología multicausal. El carácter contrario a la igualdad de esta situación se ve reforzado cuando se trata de las mujeres, ya que a menudo se encuentran en actividades en las que la trazabilidad de las exposiciones ocupacionales es menor. Por otra parte, delegados sindicales indican que no es raro que los expertos médicos (tanto en el procedimiento administrativo del FMP como en los procedimientos judiciales ante los tribunales laborales) planteen la cuestión de saber si una trabajadora tiene hijos 
para estimar la parte eventual del trabajo familiar en los trastornos musculoesqueléticos. Esta pregunta no se hace en el caso de los hombres.

\subsubsection{Filtros sucesivos}

En la práctica, la aplicación del concepto del riesgo profesional lleva al establecimiento de filtros sucesivos. El trabajador podrá ser indemnizado solamente después de superar con éxito todos los filtros. La lectura de los documentos de interpretación del FMP y de lo que retiene la jurisprudencia de los peritajes indica que generalmente se recurre a diversas disciplinas. Los datos procedentes de la epidemiología, la toxicología, la anatomopatología y las estadísticas médicas no se interrelacionan fácilmente. Cada disciplina disecciona la realidad de acuerdo con su lógica y sus clasificaciones. La probabilidad de llegar a una respuesta negativa en una de estas disciplinas es obviamente alta. La dificultad es aún mayor por el hecho de que el razonamiento se divide en dos etapas: ¿Existe el riesgo profesional sobre la base de los conocimientos médicos? ¿Se ha demostrado el riesgo profesional en relación con la situación individual del trabajador?

El enfoque definido explícitamente por el FMP para el sistema abierto indica que un solo obstáculo en la secuencia de los filtros es suficiente para obstruir el paso ${ }^{18}$. Por otra parte, los peritajes individuales conceden un lugar importante al historial médico, las características físicas, la edad, la posible práctica de un deporte, etc. Este tipo de peritaje conlleva un sesgo intrínseco que debería llevar a los jueces a tener en cuenta la duda razonable en favor de las personas aseguradas. La inteligencia clínica se basa en una relación interpersonal donde la confianza entre el médico y el paciente es sumamente importante. En un peritaje, este vínculo es inexistente. Numerosos trabajadores que se han visto envueltos en este tipo de procedimientos se quedan con la impresión de ser percibidos como "sospechosos". Su experiencia relativa a sus condiciones de trabajo disminuye en importancia en favor de medidas de carácter objetivo. Esta situación introduce un factor de desigualdad en detrimento de las mujeres, ya que para las ocupaciones que responden al estereotipo de "trabajos pesados", las exposiciones se aceptan más fácilmente que en las profesiones supuestamente más ligeras.

El establecimiento de filtros conduce a prácticas arbitrarias. En el caso de algunos códigos, el FMP admite sin mucha dificultad que las condiciones de trabajo juegan un papel decisivo. Así, para el código 1.603 relativo a las hipoacusias y sorderas causadas por el ruido, las circunstancias individuales son neutralizadas por la referencia a los valores límite de exposición. El reconocimiento de la enfermedad no planteará problema, siempre y cuando los niveles de ruido excesivo estén documentados o se beneficien de la presunción. En el caso de las enfermedades dorsolumbares la situación se invierte: las condiciones objetivas del trabajo son secundarias. Tanto la revisión del expediente por el FMP como los peritajes requeridos por los jueces conceden una atención considerable a la edad, el peso, el tamaño y otros factores individuales. El carácter arbitrario de muchos peritajes no es neutro desde una perspectiva de género. Tiende a consolidar el estereotipo de una peligrosidad menor del trabajo remunerado de las mujeres. En particular, tiende a oponer argumentos sobre las consecuencias posibles de actividades en el entorno de la familia como pruebas del carácter no determinante de las condiciones de trabajo en el desarrollo de patologías. 

en la ley ni en la lista. En cuanto al síndrome psicoorgánico causado por los solventes, el FMP considera que toda solicitud de indemnización se basa en un diagnóstico fundamentado en tres elementos: una descripción de la exposición ocupacional a solventes orgánicos, un informe neurológico o psiquiátrico que confirme el diagnóstico y un informe establecido por un médico internista que excluya otras posibles causas. Los dos primeros elementos reflejan los requisitos legales: el asegurado debe establecer la exposición y la enfermedad. El tercero, en cambio, los contradice. La condición de exclusividad de la causa profesional fue rechazada explícitamente por el Tribunal de Casación.

Los criterios definidos más recientemente para la evaluación de la exposición a riesgos laborales de tendinopatías también son cuestionables. Se basan en la lista de verificación OCRA, la cual fue elaborada para finalidades completamente distintas. Consiste únicamente en formular un diagnóstico rápido para la definición de las prioridades de prevención. Los autores de la lista de verificación indican, para aquellas puntuaciones en las que el FMP considera que el riesgo profesional es inexistente, una prevalencia significativa de las patologías de las extremidades superiores (Colombini, 2011). Así, el FMP considera que no habría ningún riesgo profesional en el caso de una puntuación de 11.1 a 14 de la lista de verificación OCRA, mientras que sus autores señalan que con una puntuación semejante entre el 8,5 y el 10,7\% de los trabajadores se verá afectado por una enfermedad de las extremidades superiores. Es decir, que existe un claro riesgo profesional. jueces han de considerar que los criterios del FMP son meramente indicativos. Sin embargo, no dejan de jugar un papel crucial en la decisión de introducir una solicitud de indemnización. Nadie quiere exponerse a la doble y difícil experiencia de pasar por los procedimientos administrativos y los recursos legales.

43 Cabe recordar a este respecto los principios establecidos en la Recomendación de la Comunidad Europea de 20 de julio de 1966: "El juego de la presunción legal establecida por la existencia de la lista de enfermedades profesionales y las condiciones de concesión de prestaciones que éstas conllevan permiten aplicar casi automáticamente disposiciones legales adoptadas en otro lugar, a falta de una definición general de la enfermedad profesional". No respetar este vínculo entre la ausencia de una definición general y el "carácter casi automático" del reconocimiento afecta a todo el equilibrio del sistema. En el caso concreto de la legislación belga, existe una incoherencia importante, ya que la legislación formuló este carácter semiautomático en términos mucho más vinculantes: los de la presunción irrefutable.

\subsubsection{Los textos reglamentarios}

\subsubsection{El listado}

El texto más importante es, obviamente, el Real Decreto de 28 de marzo de 1969, relativo la lista de enfermedades profesionales, el cual ha sido objeto de numerosas modificaciones posteriores.

El contenido de la lista corresponde en buena parte a las exposiciones tradicionales de un trabajo industrial, con excepción de factores no materiales relacionados con la organización del trabajo (horarios, intensidad, trabajo nocturno ${ }^{19}$, movimientos

Laboreal, Volume 11 N² | 2015 
repetitivos, manipulación manual de cargas, estrés postural, trabajo monótono). La mayoría de estos riesgos no se abordan o lo son solamente de forma muy restringida. No es una elección deliberadamente discriminatoria, ya que una lógica disciplinaria también juega un papel importante. Se favorecen los estudios epidemiológicos de un único factor de riesgo en un determinado grupo profesional. Los factores relativos a la organización del trabajo son mucho menos característicos de actividades profesionales específicas. Pueden determinarse, con cierto margen de incertidumbre, las actividades profesionales en las que se produce una exposición al benceno, a radiaciones ionizantes o al virus de la hepatitis. Resulta mucho más complejo rastrear otras exposiciones y la única referencia a "los conocimientos médicos" en el artículo 32 de la ley es inadecuada. Otras disciplinas tales como la ergonomía, la psicología y la sociología aportan conocimientos complementarios que permitirían tomar mejor en cuenta estos riesgos.

El único grupo de enfermedades de la lista que afecta a una gran mayoría de las mujeres es el de las enfermedades infecciosas o parasitarias. Este grupo es principalmente aplicable al sector de la atención sanitaria y las mujeres representan la gran mayoría de los trabajadores de este sector. De igual manera, se observa una mayoría de mujeres entre las personas indemnizadas a raíz de enfermedades alérgicas causadas por el látex. Hay que subrayar que, en ambos casos, se trata de patologías monocausales.

El quinto grupo de la lista se refiere a agentes físicos. Este es el grupo en el que sin duda alguna la redacción de los códigos es la más criticable. La lista solamente permite indemnizar una fracción muy reducida de todos los trastornos musculo-esqueléticos existentes. La escasa representación de las mujeres en este grupo resulta dramática.

\subsubsection{Precocidad y edad: ¿un factor de discriminación?}

48 La noción de "lesiones degenerativas precoces" formulada por el código 1.605 .12 en relación con las patologías lumbares causadas por vibraciones mecánicas es incompatible con la lógica general del sistema ${ }^{20}$. No se refiere a condiciones de exposición, sino al supuesto estado general de salud de un grupo de edad de la población. Tiende a dar lugar a una discriminación indirecta contra los trabajadores de más edad. Si dos trabajadores de 25 años y 45 años respectivamente, están sujetos a las mismas condiciones de trabajo durante el mismo período de tiempo y se ven afectados por la misma patología lumbar, el primero podrá recibir una compensación con arreglo al código 1.605.03 de la lista de enfermedades profesionales, mientras que el segundo puede verse privado de dicha indemnización ${ }^{21}$.

La preocupación por ahorrar gastos ha producido una ruptura con la coherencia global del sistema. Esta coherencia supone que la inclusión de una enfermedad en la lista crea una presunción de causalidad independiente de las características personales del trabajador. Si tuviera que adoptarse un enfoque contrario abriría la puerta a la discriminación basada en los más diversos criterios tales como la genética, el origen étnico, el sexo, los comportamientos propios de la vida privada (como el tabaquismo, escuchar música a alto volumen o practicar determinadas actividades de ocio). La literatura científica señala posibles vínculos entre ciertas enfermedades profesionales y características genéticas. Resulta difícil imaginar que las enfermedades profesionales dejen de ser indemnizadas entre los trabajadores que presenten una predisposición genética a estas patologías ${ }^{22}$. 
La coherencia jurídica de un sistema que formula una presunción de causalidad exigiría que la edad fuera excluida del debate, ya que ninguna enfermedad es causada por la edad. El criterio formulado en la lista no se refiere explícitamente a la edad. Sin embargo, la noción de "precocidad" da inevitablemente lugar a que la edad se convierta en un elemento determinante. La justificación ha sido tomada de una simple observación estadística de una mayor prevalencia de ciertas enfermedades que afectan a una parte de la población. Los datos epidemiológicos utilizados por el FMP no distinguen lo que depende de la edad como condición biológica y lo que depende como condición social (especialmente todos los efectos relacionados con un desgaste debido al trabajo y la acumulación de exposiciones profesionales a todo lo largo de la vida activa).

\subsubsection{La lista y los canceres}

51 Los cánceres de origen profesional son reconocidos actualmente como la primera causa de mortalidad relacionada con las condiciones de trabajo. Habida cuenta de la magnitud del problema, la lista actual resulta poco eficaz. Por ejemplo, no es lógico que la exposición al betún (código 1.201.03) se asocie únicamente a las patologías cutáneas cuando también es causa del cáncer de pulmón ${ }^{23}$. Las deficiencias de la lista se añaden a los criterios restrictivos de reconocimiento formulados por el FMP para determinados tipos de cáncer de la lista (en particular para el cáncer de pulmón causado por el amianto). Solo los mesoteliomas se tienen en cuenta con cierta eficacia. Representan el $54 \%$ del conjunto de cánceres reconocidos.

Entre 2001 y 2010, el FMP reconoció 1.585 cánceres como enfermedades profesionales. Las mujeres representaron solamente el $2 \%$ de los casos reconocidos (32 casos en diez años). Durante los diez años para los que se dispone de datos (2001-2010), se reconocieron poco más de 5 casos sobre 1000 como enfermedades profesionales para los hombres (en promedio, 160 tipos de cáncer por año para una morbilidad total de 30.000 nuevos casos). Para las mujeres, se alcanza el minúsculo porcentaje de menos de 2 casos de media por cada 10.000 (entre 1 y 6 cánceres reconocidos cada año para una morbilidad femenina en torno a 25.000 nuevos casos de cáncer).

Todas las estimaciones epidemiológicas atribuyen una proporción significativamente superior a los cánceres de origen profesional. En términos de exposición, las mujeres están ciertamente menos expuestas que los hombres a productos químicos cancerígenos $^{24}$. En cambio, están más expuestas que los hombres a productos citostáticos debido a la estructura del empleo en el sector sanitario. El riesgo representado por el trabajo nocturno en términos de cáncer es mayor para las mujeres que para los hombres habida cuenta de la morbilidad tan elevada que representa el cáncer de mama en las mujeres. Asimismo, tendrían que evaluarse las exposiciones profesionales a los disruptores endocrinos y a los niveles de riesgo diferenciados que pueden implicar para los hombres y las mujeres. Por lo tanto, no hay ninguna explicación objetiva en términos sanitarios que justifique esta relación de uno a cincuenta entre los cánceres femeninos y los cánceres masculinos reconocidos como enfermedades profesionales. 


\subsubsection{Los riesgos psicosociales} ellos causan son conocidas desde hace por lo menos un siglo. Al igual que con otras enfermedades profesionales, la literatura médica ha intentado dar explicaciones de muy diversa índole. Algunos autores ponen de relieve factores individuales o biológicos. Entre las dos guerras mundiales, un neurólogo estadounidense explicó la elevada prevalencia de la neurastenia entre las trabajadoras de la confección por el hecho de que un porcentaje significativo de estas trabajadoras eran judías originarias de Rusia ${ }^{25}$. Se basaba en una extensa literatura médica para atribuir el problema a factores raciales y sexuales. Otros, por el contrario, han hecho hincapié en el papel crucial de las condiciones de trabajo. Entre ellos, los estudios del psiquiatra francés Le Guillant sobre la "neurosis de las telefonistas" en la década de los años cincuenta del siglo XX. Como señala Régis Ouvrier-Bonnaz: "Le Guillant confía en la perspicacia de las propias interesadas para referir la gran complejidad de su actividad. Le Guillant toma muy en serio las reivindicaciones de las telefonistas. Pero también sabe que los esfuerzos de los trabajadores por comprender sus vivencias deben ser secundados". Para Le Guillant, "el síndrome descrito por las operadoras telefónicas no les es exclusivo, sino que afecta a 'todos los puestos de trabajo que implican, con o sin fatiga muscular, un ritmo excesivamente rápido de las operaciones así como condiciones de trabajo objetiva o subjetivamente penosas, la mecanización de los actos y la monotonía, la estrecha vigilancia, la perturbación de las relaciones humanas en la empresa" (Ouvrier-Bonnaz, 2006). encuentra ante obstáculos considerables. Estos riesgos desempeñan un papel importante en los trastornos músculos esqueléticos ${ }^{26}$ pero este factor se toma poco en cuenta en los peritajes presentados a los tribunales laborales con miras al reconocimiento de enfermedades profesionales. Más allá de su contribución a las patologías físicas se extiende un campo más amplio de enfermedades que afectan a la salud mental. El burn-out o agotamiento profesional, las depresiones, el estrés postraumático están correlacionados con los riesgos laborales.

56 La lista belga de las enfermedades profesionales nunca ha incluido ningún factor psicosocial. La posibilidad de un reconocimiento en el marco del sistema abierto está prácticamente excluida. Un estudio comparativo europeo indica que se habrían reconocido en Bélgica dos casos a lo largo de un período de quince años (Eurogip, 2013).

57 Cuando se prepararon los primeros textos en relación con la ley de 11 de junio de 2002 sobre el acoso y la violencia, se planteó la cuestión de un posible reconocimiento de las enfermedades profesionales. El Consejo para la igualdad de oportunidades entre hombres y mujeres había llamado la atención sobre este problema en su dictamen sobre el proyecto de ley. Pidió "facilitar el reconocimiento como enfermedades profesionales de las patologías derivadas de este tipo de situaciones ${ }^{27}$ " (es decir, que resultan de la violencia, el acoso moral o el acoso sexual). El Consejo pidió al ministro federal de Empleo tomar las iniciativas pertinentes en este sentido. En su declaración introductoria a la Comisión de Asuntos Sociales de la Cámara, el ministro había indicado su deseo de que las patologías derivadas de estas situaciones se admitieran en el marco de la indemnización por riesgos profesionales. En la práctica, existe desde entonces una cobertura limitada en el marco de la indemnización de accidentes de 
trabajo ${ }^{28}$. La mayoría de los casos no responden a las condiciones fijadas para obtener esta indemnización, ya que es imposible identificar un acontecimiento repentino. No se indemnizan las consecuencias del acoso y otros riesgos psicosociales en el contexto de las enfermedades profesionales.

La situación actual es paradójica. Sobre la base de las disposiciones específicas relativas al acoso moral y la violencia en el trabajo, los empleadores están obligados a organizar la prevención. Los trabajadores víctimas de una enfermedad pueden obtener una indemnización en virtud de la responsabilidad civil a través de los procedimientos judiciales establecidos por la ley. En este ámbito, la inmunidad civil del empleador carece de vigencia y los trabajadores se benefician de la adaptación de la carga de la prueba específica a esta parte de la legislación laboral en relación con el establecimiento del factor causal en la organización del trabajo.

Por lo tanto, en caso de acoso moral, las enfermedades podrán ser indemnizadas por el empleador sobre la base de su responsabilidad civil ${ }^{29}$. En caso de que estas enfermedades sean causadas por otras condiciones de riesgo psicosocial (por ejemplo, una carga de trabajo excesiva combinada con la falta de apoyo de la jerarquía), no es posible ninguna indemnización, ya sea sobre la base de la responsabilidad civil, o como parte de la indemnización por enfermedades profesionales.

\subsubsection{Otros problemas planteados por la lista}

Otro problema que plantea la lista es que no tiene en cuenta las sinergias de las exposiciones ocupacionales. Estas sinergias pueden producirse ya sea simultáneamente (lo que ocurre a menudo en el caso de los trabajadores expuestos a sustancias carcinógenas). También pueden producirse en diferentes momentos de una carrera profesional. En este último caso, el efecto de las sinergias de la exposición es particularmente importante para las patologías que se desarrollan en etapas. Por lo tanto la carcinogénesis implica varias etapas entre la mutación inicial del ADN de una célula y el desarrollo de un tumor en un órgano o la aparición de metástasis. Este proceso puede extenderse durante décadas en las que cada una de las diferentes exposiciones ocupacionales desempeña un papel en una determinada etapa. Una encuesta epidemiológica internacional entre más de 15.000 trabajadores de la construcción muestra un mayor riesgo de cáncer de pulmón en comparación con otras profesiones. Atribuyen este riesgo a la sinergia entre las diferentes exposiciones a agentes carcinógenos, en particular la sílice cristalina ${ }^{30}$ y el amianto (Consonni, 2014). En Francia, la jurisprudencia ha permitido recientemente el reconocimiento, en el sistema abierto, de un cáncer causado por una sinergia de exposiciones ocupacionales a múltiples agentes carcinógenos ${ }^{31}$.

61 Una encuesta europea estudió la relación número de enfermedades reconocidas por 100.000 trabajadores asegurados en 1990 (Eurogip, 2009). Compara diez países de la Unión Europea. Bélgica se situaba en segundo lugar en 1990, cuarto en 2000 y sexto en 2006. En comparación con Francia, Bélgica reconocía cuatro veces más enfermedades en proporción con la población incluida en 1990, pero reconoce cinco veces menos en 2006. Aun cuando se examinan los datos en un marco estrictamente nacional, la evolución es notoria al haber 184 enfermedades reconocidas por 100.000 trabajadores en 1990 y 54 en 2006, pese a la apertura del sistema a las enfermedades no incluidas en la lista y un aumento del número de patologías incluidas en dicha lista. Por lo tanto, 
existe una pérdida de eficacia procedente principalmente del carácter inadaptado de la lista y del papel marginal del sistema abierto.

\subsubsection{Una jurisprudencia incierta: el excesivo peso del peritaje}

62 La jurisprudencia concierne los conflictos individuales, que no son muy numerosos. Unos cientos de casos por año en relación con varios miles de decisiones negativas de parte del FMP y decenas de miles de enfermedades causadas por el trabajo ${ }^{32}$ que no han sido objeto de ninguna declaración ni de ninguna solicitud de indemnización. La jurisprudencia también se utiliza para interpretar las normas jurídicas. Las prácticas administrativas del FMP incluyen solo raramente las aportaciones de la jurisprudencia. Por lo tanto, es preciso recomenzar eternamente la batalla alrededor de casos individuales. No existe ningún organismo específico encargado de definir las orientaciones del FMP en lo que se refiere a procedimientos judiciales. Aun cuando no faltan los documentos que definen los criterios médicos de reconocimiento y están a disposición del público, brilla por su ausencia un análisis de la jurisprudencia.

A reserva de un análisis más sistemático, puede observarse que la jurisprudencia se divide en dos tendencias principales:

a. decisiones que se esfuerzan por mantener el principio de presunción de probabilidad; que consideran que la prueba de una enfermedad profesional puede resultar de un conjunto de índices objetivos que establecen la existencia de una patología y las condiciones de trabajo que pueden razonablemente considerarse la causa de ésta;

b. decisiones claramente inspiradas en el contenido de los peritajes y que no parecen preocuparse de las diferencias importantes que existen entre la legislación y las diferentes disciplinas invocadas.

64 Para entender el conflicto entre estos dos tipos de decisiones, cabe remitirnos a dos sentencias del tribunal laboral de Lieja adoptadas por diferentes salas en $2011^{33}$. El mérito de estas sentencias consiste en que proporcionan una descripción muy detallada de los informes de los expertos. La primera sentencia data del 11 de marzo de 2011. Se trata de un trabajador que solicita una indemnización sobre la base de la lista. Trabajó desde la edad de 21 años como conductor de autobús. Alrededor de los 51 años fue diagnosticado con lesiones degenerativas lumbares. Estas lesiones corresponden a los criterios médicos del código 1605.12 relativo a las lesiones causadas por las vibraciones mecánicas transmitidas al cuerpo por el asiento. Queda por resolver el problema de la condición de precocidad formulada por el código. En julio de 2004, el FMP rechazó su solicitud, indicando que las lesiones no responden al criterio de precocidad. El asunto se presentó al tribunal laboral, el cual ordena un peritaje cuyo contenido es refutado. El 27 de abril de 2010, el tribunal laboral ordena un nuevo peritaje. El FMP interpone recurso. La sentencia del tribunal laboral interviene 8 años después de la demanda de indemnización. Esta sentencia rechaza la demanda de indemnización y acepta los argumentos del FMP. El elemento central del razonamiento es que el peritaje desfavorable al trabajador permitiría establecer que éste no se ha visto afectado por la enfermedad incluida en el código. Sin entrar en todos los detalles, un elemento crucial del informe pericial es el siguiente: "El paciente presenta una anomalía estructural de la articulación lumbosacra. Pesa 85 kilos por 169 centímetros de altura y presenta características físicas y biomecánicas destinadas a padecer patologías lumbares, independientemente de toda exposición a un riesgo profesional". Sobre esta base, el experto escribe que "no puede establecerse la relación causal con la exposición al 
riesgo profesional". El lenguaje médico formula una duda legítima sobre el origen de la enfermedad. Contradice el criterio jurídico de la presunción. Esta contradicción aparece de lleno en una de las formulaciones del experto: "no podemos afirmar que N. presenta una degeneración que solamente habría presentado ulteriormente de no haber estado expuesto". Esta frase es una doble negación. El experto no dice que la enfermedad se hubiera producido necesariamente a esta edad, independientemente de las condiciones de trabajo. Indica que no puede afirmar lo contrario. De la inevitable duda del lenguaje médico se concluye jurídicamente que la enfermedad no es precoz. El tribunal califica los hechos de la siguiente manera: "Visto que el demandado no padece la enfermedad contemplada, es completamente irrelevante examinar la exposición al riesgo, tanto en términos de duración como frecuencia e intensidad de la misma". Desde nuestro punto de vista, la peritación prevaleció sobre los criterios jurídicos, lo que demuestra la inconsistencia del texto normativo que formula la noción de enfermedad "precoz". Si desea mantenerse un mínimo de lógica en relación con la construcción general del riesgo profesional, es difícil imaginar que en materia de accidentes de trabajo, un experto escribiera que no puede afirmar que una determinada lesión no habría aparecido sin el accidente. Se limitará a plantear la causalidad plausible entre el accidente y la lesión.

En la segunda sentencia del 2 de diciembre de 2011, un trabajador solicita una indemnización en el marco del sistema abierto. Padece una patología de las rodillas. Antes de describir con precisión la enfermedad, el experto procede a un examen detallado de las condiciones de trabajo sobre un período de trece años entre el inicio de la actividad y la introducción de la demanda de indemnización en junio de 2003. Esta actividad consistió principalmente en descargar camiones y subir regularmente escaleras llevando cargas metálicas de 18 a 20 kilos. Esta actividad de subir y bajar las escaleras con carga representa tres cuartas partes de su tiempo de trabajo de ocho horas diarias. El trabajador también estuvo expuesto a vibraciones mecánicas. El FMP hace hincapié en factores extrínsecos al trabajo propios en parte al estado de salud general y a factores personales (práctica del fútbol, en particular con un accidente, obesidad). La segunda sentencia desarrolla una argumentación jurídica mucho más detallada que la examinada por la primera sentencia. Rechaza el criterio de causalidad preponderante invocado por el FMP y desarrolla un razonamiento basado principalmente en el artículo 30 bis de las leyes coordinadas. La sentencia confirma el fallo del tribunal laboral, que reconoce la existencia de la enfermedad profesional.

Uno de los inconvenientes del excesivo lugar que ocupan los peritajes en relación con el razonamiento jurídico es la dilación de los procedimientos. En los dos casos examinados anteriormente, fueron necesarios ocho años para tomar una decisión. Cualquiera que sea el resultado, favorable o desfavorable, para el trabajador, la perspectiva de iniciar un proceso de tal duración surte un efecto disuasivo. Los médicos del trabajo a los que entrevisté comentan que aconsejan no introducir una demanda de indemnización a menos que la tasa de incapacidad sea muy elevada y que exista un riesgo significativo para el trabajador de encontrarse en paro. Desde este punto de vista, existe una desigualdad entre las partes. El FMP es una institución para la que el tiempo no es un factor crítico. Las personas enfermas cuentan por su parte solamente con la duración de una vida $\mathrm{y}$, a menudo, desean pasar página aunque para ello deban renunciar a sus derechos. Dicha desigualdad tiene efectos sinérgicos con las desigualdades de género en 
la sociedad. Un largo proceso judicial con éxito dudoso requiere un apoyo social del cual las mujeres disponen menos.

\subsubsection{Legitimidad y transparencia}

67 La relación salarial pone en peligro la salud de los trabajadores. La subordinación reduce las posibilidades de defenderse contra este peligro como podría hacerse en la vida cotidiana fuera del trabajo. Por consiguiente, el objetivo económico de la empresa (la búsqueda de beneficios) tiende a transformar la salud humana en un bien negociable, en el objeto de un contrato donde la integridad física se compra a cambio de un salario. La compleja etiología de las enfermedades es tal que una mera presunción de causalidad comparable a la que conllevan los accidentes de trabajo sería insuficiente para alcanzar los objetivos de una indemnización establecida a tanto alzado. Estos objetivos son dobles: implican una parte de reparación, pero también permiten, en determinadas condiciones (relacionadas con la incapacidad) retirarse del mercado de trabajo al tiempo que se aseguran los medios de vida. Si la presunción iuris et de iure es una ventaja innegable para el trabajador, cumple una función necesaria para equilibrar las múltiples desventajas que conlleva el sistema de indemnización: una compensación a tanto alzado que no corresponde a la totalidad del perjuicio real, una indemnización que cubre solamente un número muy limitado de daños a la salud.

Por tanto, existe una estructura general de la legislación de las enfermedades profesionales en base a estas interacciones. Naturalmente, puede desearse que el equilibrio de los derechos y obligaciones se desplace a favor de una $\mathrm{u}$ otra de las partes, pero en ese caso es necesario recuperar un todo coherente.

En última instancia, el examen de la legislación sobre las enfermedades profesionales permite abordar la cuestión de la legitimidad del derecho positivo. Tradicionalmente, las respuestas de la filosofía del derecho se sitúan entre dos extremos. En uno, se encuentra una visión positivista que reduce la legitimidad de la norma al respeto de las condiciones jurídicas de su producción. En el otro extremo, está una concepción instrumental que evalúa la ley en términos de su utilidad para cumplir otros objetivos de la sociedad en general o de determinados grupos sociales. Estos objetivos darían pie a una búsqueda de legitimidad que concede prioridad a factores extra jurídicos: la economía, el orden público, la acumulación de riqueza por una parte u otra, su distribución entre todos. A la luz de la experiencia histórica del siglo XX, Chaïm Perelman tuvo que llegar a la conclusión de que un criterio jurídico esencial es el imperativo de verosimilitud. Una norma jurídica no formula una descripción de la realidad. La norma jurídica establece objetivos, los cuales pueden cumplirlos de manera imperfecta. No obstante, no deja de estar sujeto a un criterio de legitimidad que establece una coherencia entre el contenido de la norma, la aprehensión de la realidad que ésta regula y la dinámica que implica en función de los objetivos perseguidos.

Este imperativo de coherencia se sitúa a varios niveles: en la norma propiamente dicha (entre sus diversas disposiciones), en su aplicación (entre los objetivos del legislador y el marco que define la norma para los procedimientos administrativos o judiciales) y en su lugar dentro de todo el sistema jurídico en relación con otras normas.

71 En lo que respecta a estos tres criterios, la regulación jurídica de la indemnización de las enfermedades profesionales es cada vez más cuestionable. 
72 La coherencia interna es endeble. El principio de presunción no concuerda bien con los criterios adoptados para la definición del riesgo laboral en el artículo 32 de la ley. La inmunidad civil es igualmente fundamental: se formula como una excepción, pero las condiciones que la rigen la convierten en la norma única. La coherencia en la aplicación no resulta menos problemática: es en gran medida una derecho sin derecho, una especie de juego de espejos infinito entre el derecho y la medicina, donde ambas disciplinas salen perdiendo. Si se examina el lugar que ocupa este ámbito de la ley en relación con las esferas contiguas, se justifican las más grandes dudas: una distancia cada vez más grande en relación con la regulación de la prevención en los lugares de trabajo, una contradicción innegable con el principio de igualdad entre hombres y mujeres.

Cabe interrogarse sobre la conformidad en relación con el derecho comunitario en materia de discriminación. Si la jurisprudencia del Tribunal de Justicia de la Unión Europea admite que aquello que denomina objetivos legítimos de política social puedan conllevar desigualdades, no deja de formular, cada vez con mayor firmeza, exigencias de transparencia, coherencia y proporcionalidad ${ }^{34}$. Cuando una determinada sección de su regulación produce desigualdades, corresponde al Estado interesado aportar la prueba de que las normas obedecen a estas exigencias. El análisis del derecho belga relativo a la indemnización de las enfermedades profesionales indica que estos criterios no se cumplen.

\section{Conclusiones}

74 Si la parte de las mujeres se limitase al $10 \%$ de la nómina, las pensiones o las prestaciones por desempleo, todas las partes interesadas considerarían que es preciso analizar la situación con toda urgencia y sobretodo actuar. Sería una cuestión ineludible para el ámbito político, la negociación colectiva y la investigación universitaria.

Desde que existen estadísticas por sexo sobre la indemnización de las enfermedades profesionales, las cifras son de dominio público. Los informes anuales del FMP reflejan el alcance de la desigualdad entre hombres y mujeres, pero se abstienen de analizar las razones. En trece años ${ }^{35}$, la magnitud del alcance no se ha modificado significativamente. Esta desigualdad no se limita a la herencia del pasado, por lo que solamente puede reproducirse sobre la base de la legislación vigente. La desigualdad que concierne las nuevas decisiones adoptadas cada año muestra que, sin una reforma, la desigualdad resultante de 50 años de aplicación de la Ley de 1963 seguirá vigente.

El Consejo para la Igualdad de Oportunidades entre Hombres y Mujeres aprobó un dictamen en junio de 2001 relativo a las repercusiones de las condiciones de trabajo en la salud y el género. Abordaba la desigualdad en materia de reconocimiento de las enfermedades profesionales ${ }^{36}$. Un segundo dictamen aprobado el 16 de abril de $2013^{37}$ señala: "El Consejo expresa su preocupación por tener que constatar que casi todas las recomendaciones emitidas, hace más de diez años, en su Dictamen núm. 45 siguen siendo pertinentes". Esta crítica no obtuvo ninguna respuesta, ni del FMP, ni del Ministerio de Asuntos Sociales. Por su parte, la Cámara de Representantes recibió una propuesta de resolución sobre este tema el 21 de marzo de $2012^{38}$, pero no ha encontrado el tiempo para incluirla en su orden del día. 
77 El presente artículo apoya la hipótesis de una discriminación sistemática contra las mujeres en lo que se refiere al reconocimiento de las enfermedades profesionales. No se trata de una situación específica a Bélgica. En Bélgica, se ve agravada por dos factores: la pérdida global de eficacia del sistema (tanto para los hombres como para las mujeres); y la ausencia de políticas específicas de igualdad en la actuación de los numerosos agentes que intervienen en el reconocimiento de las enfermedades profesionales.

78 La comparación con Francia es elocuente. Sin pretender que la hierba siempre es más verde en el jardín de al lado, puede constatarse que en el curso de quince años, Francia ha recuperado un retraso importante en estos dos ámbitos. El sistema de indemnización opera para un número creciente de trabajadores y de acuerdo a perfiles de riesgo que reflejan mejor los conocimientos actuales en materia de salud en el trabajo $^{39}$. La desigualdad entre hombres y mujeres se ha reducido. Actualmente, en Francia, las mujeres constituyen aproximadamente la mitad de los nuevos casos de enfermedades profesionales. El proceso de cambio en Francia reside en una voluntad muy firme de los sindicatos de participar en la discusión científica y en que disponen de sus propios expertos en un contexto en donde el escándalo del amianto impide todo retorno a la normalidad anterior de una paz social a expensas de la salud en el trabajo (Deplaude, 2003). Esta experiencia indica que existe una relación entre igualdad de género y un mejoramiento general de la eficacia de los dispositivos que cubren la población en general. La dominación masculina no es una excepción a la dialéctica del amo y el esclavo.

79 En lo relativo a las enfermedades profesionales, la discriminación es indirecta. Es el resultado de factores que no se formulan sobre la base del género. Es una discriminación sistémica ya que ninguno de los factores analizados en el presente artículo permite, por sí solo, explicar la magnitud de las desigualdades. Lo que resulta determinante es la combinación de su dinámica.

80 Entre los factores jurídicos, cabe mencionar: una legislación poco coherente, la insuficiente calidad de la redacción legislativa y textos normativos cuya redacción ha sido delegada a la institución responsable de su puesta en práctica; el fracaso del sistema abierto a compensar el hecho de que la lista corresponda en mayor medida a los empleos masculinos en las industrias tradicionales que a la realidad del trabajo contemporáneo. El proceso de reconocimiento discrimina a las personas que han tenido una trayectoria profesional irregular o inestable (precariedad del empleo, trabajo a tiempo parcial). Los empleos "periféricos", tales como la limpieza, el envasado, el embalaje y condicionamiento, el mantenimiento y el almacenamiento se abordan de forma inadecuada. La trazabilidad de la exposición es muy desigual después de la actividad profesional. Las referencias legislativas al estado de salud de la población en general (art. 62), así como la definición del riesgo profesional que conlleva contribuyen a la inseguridad jurídica. La ley tiende a someter el trabajo de los jueces a un requerimiento contradictorio: razonar sobre la base de una presunción irrefutable de causalidad entre las exposiciones y las enfermedades, por una parte, y confirmar la existencia de una relación causal preponderante, por otra, antes de poder calificar la exposición de un determinado grupo como riesgo profesional. El trabajo de calificación de los jueces se debate entre la lógica social y colectiva de la ley y un análisis individualizado. Esta situación a menudo conduce a delegar la misión de administrar justicia a peritajes que confunden la causalidad jurídica con las múltiples variantes de 
la causalidad médica. La crítica más importante que puede formularse en relación con la legislación de la indemnización por enfermedades profesionales es que induce a asumir la inexistencia de todo fundamento jurídico. Esta situación es a la vez causa y efecto de una gran confusión entre el lenguaje de la ley y el de las diferentes disciplinas sanitarias. Una transposición mecánica de la duda legítima de la ciencia conduce a la arbitrariedad de la ley.

81 El derecho belga de responsabilidad civil ha definido criterios de causalidad legales que consisten en la teoría de la equivalencia de las condiciones. Significa que es preciso analizar toda la cadena de acontecimientos que contribuyeron a la aparición de un daño. Una vez que aparezca un hecho generador de la responsabilidad como una de las causas del daño, ya no importa comprobar si otras causas contribuyeron a dicho daño, ni en qué medida pudieron haberlo hecho. Tanto las prácticas administrativas del FMP como una parte importante de la jurisprudencia sobre las enfermedades profesionales se alejan considerablemente de esta interpretación jurídica de la causalidad. Es innegable que existe una paradoja. En términos de riesgos laborales, la razón de ser de una legislación específica es facilitar el acceso a la indemnización en relación con las disposiciones de la aplicación del derecho común de la responsabilidad civil, lo que justifica primordialmente el establecimiento de presunciones irrefutables para las enfermedades que figuran en la lista. En la práctica, la simple aplicación de la teoría de la equivalencia de las condiciones daría lugar a indemnizaciones más frecuentes.

Los factores no jurídicos no son menos importantes. Se integran en un contexto global de invisibilidad social, política e institucional de los riesgos laborales entre las mujeres. Cabe enumerar algunos: una investigación médica poco sensible a la dimensión de género de la salud en el trabajo; la escasa participación de los sindicatos en las controversias científicas; las deficiencias observadas en la actividad de los servicios de prevención, etc. El peso de la carga de la prueba en los procedimientos administrativos tanto como en el litigio judicial se ve amplificado por la ansiedad psicológica, el aislamiento social y la debilidad física de las personas enfermas. La tramitación de las solicitudes a menudo es una carrera de obstáculos, vista con malos ojos por los médicos que la consideran una sobrecarga administrativa. Para los pacientes, someterse a los peritajes con el único propósito de obtener una indemnización es una prueba agotadora, se equipara a una negación del drama de la enfermedad. Plantea la duda de haber sacrificado su salud para ganarse la vida. Estos factores psicológicos no son individuales, se ven reforzados por la condición social. Una trabajadora de la limpieza se encuentra en una situación menos favorable que un ingeniero nuclear, ya que no domina el lenguaje de los peritos.

83 Algunos de estos factores son anteriores al sistema de reconocimiento de las enfermedades profesionales, es decir: la segregación profesional; los estereotipos según los cuales el trabajo de la mujer es ligero; la insuficiencia de recursos asignados al control de la aplicación de las normas de prevención; la prioridad acordada a los accidentes en comparación con las enfermedades. La compartimentación entre los tres ámbitos de actuación que son la salud en el trabajo, la igualdad de género y la salud pública dificulta el que se tengan en cuenta de manera coherente las condiciones de trabajo entre los elementos que generan globalmente las desigualdades.

La multitud de factores examinados no debería justificar la inacción con el pretexto de que han de introducirse demasiadas reformas y que éstas afectarían a un gran número de interesados diferentes. Una serie de mejoras limitadas puede contribuir a una 
dinámica positiva. Sería ilusorio esperar un plan de acción ideal y completo. Una revisión crítica de la lista de enfermedades profesionales, a la luz de un análisis de género, tener en cuenta los efectos de las exposiciones múltiples, así como mejorar el sistema abierto, son tres eslabones importantes aun cuando debiera considerarse una reforma más ambiciosa.

\section{BIBLIOGRAFÍA}

Cavet, M. \& Léonard, M. (2013). Les expositions aux produits chimiques cancérogènes en 2010, DARES-Analyses, $\mathrm{n}^{\circ}$ 54, 1-9.

Colombini D., Occhipinti E, Cerbai M. , Battevi N. \& Placci M., (2011). Aggiornamento di procedure e di criteri di applicazione della Checklist OCRA. Medicina del Lavoro, $\mathrm{n}^{\circ}$ 102, 1-38.

Consonni, D., De Matteis S, Pesatori AC, Bertazzi PA, Olsson AC, Kromhout H, Peters S, Vermeulen RC, Pesch B, Brüning T, Kendzia B, Behrens T, Stücker I, Guida F, Wichmann HE, Brüske I, Landi MT, Caporaso NE, Gustavsson P, Plato N, Tse LA, Yu IT, Jöckel KH, Ahrens W, Pohlabeln H, Merletti F, Richiardi L, Simonato L, Forastiere F, Siemiatycki J, Parent MÉ, Tardón A, Boffetta P, Zaridze D, Chen Y, Field JK, 't Mannetje A, Pearce N, McLaughlin J, Demers P, Lissowska J, Szeszenia-Dabrowska N, Bencko V, Foretova L, Janout V, Rudnai P, Fabiánová E, Stanescu Dumitru R, Bueno-de-Mesquita HB, Schüz J, \& Straif K. (2014). Lung cancer risk among bricklayers in a pooled analysis of case-control studies. International Journal of Cancer, 136 (2), 360-371.

De Brucq, D. (1999). Maladie professionnelle hors liste, condition de causalité, arrêt de la Cour de cassation, 2 février 1998, FMP c/ V. Revue Belge de Sécurité Sociale, 3-1999, 573-588.

Delooz, P. \& Kreit, D. (2008). Les maladies professionnelles. Bruxelles: Larcier.

Dembe, A.E. (1996). Occupation and disease: how social factors affect the conception of work related disorders. New Haven: Yale University Press.

Déplaude, M.O. (2003). Codifier les maladies professionnelles: les usages conflictuels de l'expertise médicale. Revue française de science politique, vol. 53, 707-738.

EUROGIP (2009). Les maladies professionnelles en Europe: statistiques 1990-2006 et actualité juridique. Paris : Eurogip.

EUROGIP (2013). Quelle reconnaissance des pathologies psychiques liées au travail ? Une étude sur 10 pays européens. Paris: Eurogip.

Jorland, G. (2005). L'hygiène professionnelle en France au XIXe siècle. Le Mouvement Social, $\mathrm{n}^{\circ} 213$, 71-90.

Lippel, K. (2015). In, A. Thébaud-Mony, P. Davezies, S. Volkoff \& L. Vogel. Les risques du travail. Pour ne pas perdre sa vie à la gagner (pp. 522-525). Paris: La Découverte.

Messing, K. (1998). La santé des travailleuses : la science est-elle aveugle ? Montréal-Toulouse: Éditions du remueménage-Octares. 
Messing, K. (2015). Ce genre qui cache les risques qu'on ne saurait voir. In, A. Thébaud-Mony, P. Davezies, S. Volkoff \& L. Vogel. Les risques du travail. Pour ne pas perdre sa vie à la gagner (pp. 106-115). Paris: La Découverte.

Ouvrier-Bonnaz, R. (2006). L. Le Guillant, Le drame humain du travail. Essais de psychopathologie du travail. L'orientation scolaire et professionnelle, 35(4), 597-600.

Perelman, Ch. (1976). Logique juridique. Nouvelle rhétorique. Paris: Dalloz.

Probst, I. (2009). La dimension de genre dans la reconnaissance des TMS comme maladies professionnelles, Perspectives interdisciplinaires sur le travail et la santé, Vol 11(2) (Consultado el 12 de octubre de 2015 http://www.pistes.uqam.ca).

Remouchamps, S. (2014). L'indemnisation des dommages générés par les incidents psychosociaux dans les régimes de réparation des risques professionnels. In, D. Dumont \& P.P. Van Gehuchten. Actualités en matière de bien-être au travail (pp.173-286). Bruxelles: Larcier.

Thébaud-Mony, A. (2008). Construire la visibilité des cancers professionnels. Une enquête permanente en Seine-Saint-Denis. Revue française des affaires sociales, 2-3, 237-254.

Ugeux, J. (1995). L'assurance contre les maladies professionnelles. In, Cinquante ans de sécurité sociale...et après?, vol. 5 : Quand le travail nuit à la santé (pp. 11-42). Bruxelles: Bruylant.

Vandenbrande, T. Vandekerckhove S., Vendramin P, Valenduc G, Huys R, Van Hootegem G, Hansez I, Vanroelen, Puig-Barrachina V, Bosmans K \&, De Witte H. (2013). Qualité du travail et de l'emploi en Belgique. Bruxelles: SPF Emploi.

Verger, P., Viau, A., Arnaud, S., Cabut S, Saliba ML, Iarmarcovai G, \&, Souville M. (2008). Barriers to physician reporting of workers' compensation cases in France, International Journal of Occupational and Environmental Health, 14 (3), 198-205.

Vogel, L. (2011). Femmes et maladies professionnelles. Le cas de la Belgique, Bruxelles: ETUI.

Vogel, L. (2014). Un espejo deformante: apuntes históricos sobre la construcción jurídica de las enfermedades profesionales en Bélgica. Laboreal, 10 (2), 10-26. http://dx.doi.org/10.15667/ laborealx0214lv

Vogel, L. (2015). Femmes et maladies professionnelles : une invibilité construite. In: A. ThébaudMony, P. Davezies, S. Volkoff \& L. Vogel., Les risques du travail. Pour ne pas perdre sa vie à la gagner (pp. 116-119). Paris: La Découverte.

\section{NOTAS}

1. No voy a repetir aquí el análisis estadístico más completo que figura en mi informe de 2011 (L. Vogel, op. cit., 2011). El texto completo puede consultarse libremente en el sitio: http:// www.etui.org/fr/Publications2/Rapports/Femmes-et-maladies-professionnelles.-Le-cas-de-laBelgique

2. Durante la redacción inicial de este artículo, solo se disponía de datos hasta 2012. Su revisión me permitió integrar datos relativos a los años 2013 y 2014. Me pareció interesante comprobar en el plano estadístico cuáles habían sido los primeros efectos de la inclusión de una tendinitis en la lista del conjunto de todos los grupos profesionales. Volveré a estos resultados en las conclusiones.

3. En Bélgica, la función pública no está cubierta por el Fondo de Enfermedades Profesionales, salvo en lo que respecta a las administraciones municipales y provinciales. 
4. Verger et al. (2008) analiza los factores que contribuyen a la subdeclaración de enfermedades profesionales por la medicina del trabajo en Francia.

5. Sobre la creación de sistema abierto en 1990, véase Vogel, 2014. El sistema abierto debería hacer posible el reconocimiento de cualquier enfermedad que no esté incluido en la lista, o para aquellas exposiciones ocupacionales que no se ajustan a las condiciones establecidas por la lista. La víctima está obligada a aportar tres elementos de prueba: la existencia de una patología, las condiciones de trabajo y la relación causal preponderante entre las condiciones de trabajo y la patología. Esta triple carga de la prueba hace que sea prácticamente imposible reconocer las enfermedades cuya etiología es compleja.

6. Las estadísticas del FMP no dan indicaciones precisas sobre las diferentes patologías declaradas en el marco del sistema abierto. Su número es relativamente estable, por lo general oscila entre 200 y 300 desde 2002, con un pico inusual de 392 en 2011.

7. En Bélgica, las mutuas median entre las personas afiliadas a la seguridad social y el organismo de ésta que reembolsa la atención sanitaria y desembolsan las prestaciones en caso de incapacidad. Cada persona está afiliada a una mutua de acuerdo con su elección personal. Históricamente, las principales mutuas están vinculadas a los fondos de ayuda mutua creados por el movimiento obrero en el siglo XIX.

8. Puede compararse con los porcentajes de 1984. En esa época, las mutuas fueron las que se ocuparon de más de la mitad de las solicitudes, mientras que los médicos del trabajo desempeñaron un papel totalmente marginal con menos del $1 \%$ de las solicitudes introducidas.

9. Para los "datos en términos de stock", la actualización que toma en cuenta las estadísticas de 2013 no presenta ningún interés particular. Será preciso esperar varios años antes de que puedan sacarse conclusiones pertinentes relativas al reconocimiento de la tendinitis.

10. Para datos más completos sobre las condiciones de trabajo y su impacto en la salud de los trabajadores véase: Vandenbrande et al., 2013.

11. Para los análisis sociológicos véase: Thébaud-Mony, 2008 y Probst, 2009.

12. El examen de los informes estadísticos anuales del FMP muestra que esta fuente de financiación es inexistente... y con razón.

13. En su versión actualmente en vigor, el artículo 51 de las leyes coordinadas asimila a la culpa intencional una situación en la que un inspector de trabajo haya procedido a una advertencia por escrito relativa al peligro que provocará la enfermedad y que el empleador haya seguido exponiendo a los trabajadores a dicho riesgo.

14. La sentencia de 24 de enero de 1995, el Tribunal de Casación (Pas., 1995, I, pp. 67 y sig.) aplica esta norma. La sentencia se refería a un trabajador de Amoco Fina expuesto al benceno. Este trabajador solicitó una indemnización por daño psicológico y moral y se consideró que la lesión actual no era el resultado de una enfermedad profesional, sino de otros factores, tales como los efectos secundarios de los análisis, la probabilidad de la enfermedad y la reducción de la esperanza de vida.

15. Véase, en particular, la sentencia del Consejo de Estado de 1 de julio de 2009 que juzgó ilegal el Decreto $n^{\circ}$ 2007-1754 de 13 de diciembre de 2007 (asunto $n^{\circ}$ 313243). Este texto sometía el reconocimiento de los cánceres pulmonares causados por el cadmio a un tiempo de latencia mínimo de 20 años entre el período de exposición y la aparición del cáncer. El recurso de anulación fue presentado por los principales sindicatos franceses.

16. Ley de 21 de diciembre de 1994 y Ley de 13 de julio de 2006. Nuestra crítica de la revisión de 2006 figura en el apartado 1.2.3.4

17. Este punto no se desarrollará dentro del marco de este artículo. Puede encontrarse una exposición sistemática en Messing, 1998.

18. Véase un resumen de este enfoque en Delooz y Kreit (2008). El texto completo de los criterios aplicados por el FMP está incluido en el dictamen del Consejo Técnico del FMP de noviembre de 
1997 sobre el sistema abierto, la exigencia de causalidad y la noción de enfermedad: Le système ouvert. L'exigence de causalité. La notion de « maladie ».

19. El trabajo nocturno está clasificado como probable factor carcinógeno por la Agencia Internacional para la Investigación sobre el Cáncer. En Dinamarca, el reconocimiento del cáncer de mama es posible para las ocupaciones femeninas expuestas durante un largo período al trabajo nocturno.

20. El cambio en la definición del Código se llevó a cabo por el Real Decreto de 27 de diciembre de 2004. La misma crítica se refiere al código de 1.605 .03 que plantea la condición de precocidad para el reconocimiento precoz de la espondilosis.

21. Sería útil presentar una cuestión prejudicial al Tribunal de Justicia de la Unión Europea sobre la compatibilidad entre esta condición de precocidad, que inevitablemente se relaciona con la edad, y las disposiciones de la Directiva 2000/7.

22. Según el dictamen pericial colectivo de la Agencia nacional de seguridad de los alimentos, medio ambiente, trabajo (ANSES, organismo público francés) publicado en septiembre de 2013: "Se observó una asociación positiva entre la exposición ocupacional a ligantes bituminosos y sus emisiones y la aparición de cánceres de pulmón y del tracto digestivo superior (cavidad oral, faringe, esófago y laringe) entre los trabajadores durante la instalaciones de productos de sellado o pavimentación". La recomendación europea 2003/670 de septiembre de 2003 menciona en la lista II: "enfermedades broncopulmonares y Cáceres broncopulmonares secundarios a la exposición de productos bituminosos." Los Estados miembros deben tomar medidas para introducir en su legislación nacional un derecho de indemnización para estas enfermedades.

23. Según el dictamen pericial colectivo de la Agencia nacional de seguridad de los alimentos, medio ambiente, trabajo (ANSES, organismo público francés) publicado en septiembre de 2013: "Se observó una asociación positiva entre la exposición ocupacional a ligantes bituminosos y sus emisiones y la aparición de cánceres de pulmón y del tracto digestivo superior (cavidad oral, faringe, esófago y laringe) entre los trabajadores durante la instalaciones de productos de sellado o pavimentación". La recomendación europea 2003/670 de septiembre de 2003 menciona en la lista II: "enfermedades broncopulmonares y Cáceres broncopulmonares secundarios a la exposición de productos bituminosos." Los Estados miembros deben tomar medidas para introducir en su legislación nacional un derecho de indemnización para estas enfermedades.

24. No se dispone de cifras para Bélgica. El ministerio de Trabajo recibe informes de los servicios preventivos de vigilancia sanitaria, pero no publica estadísticas sobre este tema. La encuesta francesa SUMER de 2010, que es una buena fuente de información, señala que el 16,1\% de los hombres y el 2,8\% de las mujeres estuvieron expuestos profesionalmente a productos químicos carcinógenos (Cavet, Léonard, 2013). Cabe suponer que la estructura del empleo y las condiciones de trabajo en Bélgica no difieren significativamente de los de Francia en relación con este tema.

25. Se trata de la obra del Dr. James Huddleson resumida por Dembe (1998), pp. 50-52.

26. Desde la década de los años 1980, esta asociación se ha destacado en numerosas investigaciones.

27. Doc. Parl., Cámara, 2001-02, n 50 1583/002.

28. Para un análisis de conjunto, véase Remouchamps (2014).

29. Trib. Trav. Tongres, 28 de junio de 2007, Chronique de Droit Social, p. 743, nota Brasseur. Este juicio concedió una indemnización de 10.000 euros. Se utilizaron varios elementos para calcular los daños, incluyendo el estrés y la depresión severa que dio lugar a un período de incapacidad laboral.

30. La lista belga no menciona los cánceres causados por la inhalación de sílice cristalina.

31. El Tribunal de casos de seguridad social, Lyon, 9 de abril 2014, decisión 2308/2014.

32. El número exacto de estas enfermedades causadas por el trabajo es obviamente incierto. Lo que importa es el alcance de la magnitud. Pueden utilizarse tres fuentes principales: encuestas sobre condiciones de trabajo en 2010 que indicaban que el 21,3\% de los trabajadores en Bélgica 
consideró que sus condiciones de trabajo afectaban negativamente a su salud; estudios epidemiológicos que atribuyen una relación causal entre una fracción específica de las enfermedades y las condiciones de trabajo y la comparación con los datos de los países vecinos. Cualquiera que sea la metodología elegida, se obtiene una enorme discrepancia entre enfermedades declaradas, o que son objeto de una demanda de indemnización y las enfermedades reconocidas por fuentes independientes del sistema de compensación.

33. Se han publicado largos extractos de estas dos sentencias con un detallado comentario: S. Gilson, Preuve des maladies professionnelles dans la liste et hors liste, Recueil de jurisprudence du Forum de l'assurance, 2011, pp. 428-450.

34. Estas exigencias se formulan con precisión en un caso relativo a las discriminaciones por motivos de edad en la legislación húngara sobre la jubilación de los jueces (TJCE, Comisión v/ Hungría, 26 de noviembre de 2012, C-286/12).

35. Los informes estadísticos anuales del FMP contienen datos desglosados por género desde 2002.

36. Dictamen $n^{\circ} 45$ de 26 de junio de 2001 del Consejo para la igualdad de oportunidades entre hombres y mujeres sobre el impacto de las condiciones de trabajo en relación con "el género y la salud".

37. Dictamen $\mathrm{n}^{\circ} 134$ de 16 de abril de 2013 de la Oficina del Consejo para la igualdad de oportunidades entre hombres y mujeres en materia de igualdad de trato entre hombres y mujeres en las enfermedades profesionales.

38. Doc. Parl., Cámara, 2011-12, n53 -2118/001.

39. Subsisten dificultades considerables para los cánceres causados por factores distintos al amianto y los problemas de salud relacionados con los riesgos psicosociales.

\section{RESÚMENES}

El Sistema belga de indemnización de enfermedades profesionales produce desigualdades masivas entre hombres y mujeres. La indemnización de incapacidades permanentes constituye la mayor parte del presupuesto del Fondo de enfermedades profesionales. Los casos indemnizados representan aproximadamente $90 \%$ de hombres y $10 \%$ de mujeres. Este artículo formula hipótesis sobre los mecanismos jurídicos de la producción de desigualdades. Destaca el papel de los expertos médicos a nivel colectivo (en la definición de enfermedades de la lista) y a nivel individual (en la aceptación o el rechazo de las solicitudes de indemnización). El sub-registro de enfermedades profesionales de las trabajadoras contribuye a un círculo vicioso: la prevención se organiza menos sistemáticamente en muchas profesiones femeninas y consolida el estereotipo según el cual las profesiones femeninas presentarían riesgos menores desde el punto de vista de la salud laboral.

O Sistema belga de indemnização de doenças profissionais produz desigualdades massivas entre homens e mulheres. A indemnização das incapacidades permanentes causadas por uma doença profissional constitui a maior parte do seu orçamento. Os casos indemnizados representam aproximadamente $90 \%$ de homens e $10 \%$ de mulheres. Este artigo formula hipóteses sobre os mecanismos jurídicos de produção dessas desigualdades. Destaca o papel essencial desempenhado pelos especialistas médicos, tanto ao nível coletivo (na definição das doenças que constam na lista de doenças profissionais), como ao nível individual (nas decisões de aceitação ou 
de rejeição dos pedidos de indemnização. O sub-reconhecimento das doenças profissionais das trabalhadoras cria um ciclo vicioso: a prevenção é menos sistematicamente organizada em muitas profissões femininas e isso ajuda a reforçar o estereótipo segundo o qual as profissões femininas seriam geralmente menos arriscadas do ponto de vista da saúde no trabalho.

Le système belge d'indemnisation des maladies professionnelles produit des inégalités massives entre hommes et femmes. L'indemnisation des incapacités permanentes causées par une maladie professionnelle constitue la part essentielle de son budget. Les cas indemnisés représentent environ $90 \%$ d'hommes et $10 \%$ de femmes. Le présent article présente des hypothèses concernant les mécanismes juridiques de production de ces inégalités. Il met en évidence le rôle essentiel joué par des expertises médicales tant au niveau collectif (dans la définition des maladies qui se trouvent sur la liste des maladies professionnelles) qu'au niveau individuel (dans les décisions d'acceptation ou de rejet des demandes d'indemnisation). La sous-reconnaissance des maladies professionnelles des travailleuses crée un cercle vicieux : la prévention est organisée de manière moins systématique dans de nombreuses professions féminines et cela contribue à renforcer le stéréotype selon lequel les professions féminines seraient généralement moins risquées du point de vue de la santé au travail.

The Belgian occupational diseases compensation system results in massive inequalities between men and women. The compensation of permanent work disabilities caused by occupational diseases represents accounts for the major part of the budget of the Occupational Diseases Fund. On 10 compensated cases, there are approximately 9 men and one woman. This paper develops hypothesis on the legal mechanisms which cause such inequalities. It underlines the role played by medical expertise at collective level (in the definition of a list of occupational diseases) and at individual level (in the decisions of accepting or rejecting workers' claims). The sub-registration of occupational diseases for women contributes to a vicious circle: prevention is less systematically organized in numerous female jobs and this situation strengthens the stereotype that female jobs are at lower risk from the point of view of occupational health.

\section{ÍNDICE}

Mots-clés: inégalités de genre, maladies professionnelles, sécurité sociale

Palavras-chave: desigualdades de género, doenças profissionais, segurança social

Palabras claves: desigualdades de género, enfermedades profesionales, seguridad social

Keywords: gender inequality, occupational diseases, social security

\section{AUTOR}

\section{LAURENT VOGEL}

Unité 'Conditions de travail, santé et sécurité', European Trade Union Institute (ETUI), Bd du Roi Albert II, 5, 1210 Brussels, Belgium

lvogel@etui.org 